\title{
DISCRIMINACIÓN EN CONTRA DE ENFERMERAS
}

\author{
Julio MENDIGURE FERNÁNDEZ1
}

En los últimos meses los médicos del hospital La Caleta de Chimbote protagonizaron enfrentamientos con personal del hospital, además de acosar, maltratar y agredir a una enfermera por el solo hecho de haber sido designada directora de ese nosocomio. Estos incidentes fueron constantes por más de tres meses, con el agravante de que sus injustificadas e inoportunas paralizaciones y prolongada huelga local perjudicaron a los pacientes y en especial a los más pobres.

Los médicos sostienen que el cargo de director de hospital sólo pueden ser ocupados por ellos, desconociendo que el Art. $9^{\circ}$ de la Ley No 27669 - Ley del Trabajo de la Enfermera, establece que la enfermera(o) tiene derecho a acceder a cargos de dirección y gerencia en igualdad de condiciones que los demás profesionales de la salud y similar en instituciones públicas y privadas.

Esta anacrónica y desfasada idea, tal vez tiene explicación en que el sistema de salud peruano está extremadamente medicalizado. Pero, además las enfermeras, son mayoritariamente mujeres y es bien sabido que las mujeres han tenido históricamente un plus de penalización social por razones de género. Por tanto, coexistiría una doble discriminación por ser mujer y por ser enfermera.

Si bien, el médico siempre ha sido el privilegiado en dirigir la gestión hospitalaria en los establecimientos de salud, ahora ya no se habla de médicos y profesionales no médicos de la salud, sino de profesionales de la salud, que son doce profesiones vinculadas a la salud y todos estos profesionales tienen el mismo derecho de acceder a tales cargos.

La hegemonía médica es evidente, puesto que el poder sanitario está, más del 98\%, en manos de hombres médicos. Basta revisar el directorio de principales funcionarios del MINSA, EsSalud, Sanidades y Clínicas Privadas, cuyas conducciones están en manos de un médico, y cuesta trabajo encontrar una enfermera en puestos de decisión y valor estratégico, pese a ser numéricamente mayoría en el sector salud y su contribución de mayor impacto en la salud pública.

El máximo órgano de Dirección de Enfermería son las direcciones o jefaturas de los Departamentos de Enfermería, no alcanzando un mayor nivel a pesar de tener a cargo el 40\% del personal de salud, con 24 horas de atención; en los hospitales nacionales sobrepasan 1000 personas entre enfermeras y técnicos, en tanto que las direcciones o gerencias de línea están reservadas para los médicos, que en la práctica el número de personal y número de camas a cargo no llega ni al 10\% de lo que administra una Enfermera Directora o jefa de Departamento de Enfermería.

Aunque entre los profesionales de Enfermería que están en importantes cargos directivos, éstos vienen demostrando capacidad y mérito para no ser discriminados, la discriminación de las enfermeras no sólo está referida a la conducción y gobierno de hospitales, también están discriminadas en el reconocimiento social, en las condiciones de trabajo (el 95\% de los médicos del MINSA están nombrados antes el 30\% de enfermeras); en la formación: los internos de medicina reciben una remuneración básica y alimentación antes las internas de Enfermería no perciben remuneración alguna ni alimentación); en relación a la especialización (el Ministerio de Salud invierte unos 100 millones de soles por año en el residentado de los médicos antes cero soles en enfermería). Las prestaciones asistenciales de enfermería se caracterizan por un cuidado integral y continuo a los pacientes, cerciorándose, en la mayoría de los casos, de ambientes confortables con vestidores, el horario y permanencia antes el personal médico cuya visita al paciente es una vez al día o al llamado pero gozan de mejores condiciones de infraestructura. En el aspecto administrativo las jefaturas médicas cuentan con una secretaria antes la jefa de enfermeras quien tiene un promedio de 80 personas a su cargo pero no cuenta con ese apoyo; y por supuesto, el listado podría ser más extenso.

${ }^{1}$ Enfermero, Magíster en Salud Pública con Mención Materno Infantil. Decano Nacional del Colegio de Enfermeras(os) del Perú 
La discriminación como un acto de segregación mediante el cual se resta oportunidades, por el hecho de ser mujer y enfermera no es admitida por el Colegio de Enfermeras(os) del Perú, por eso en reiteradas oportunidades se ha denunciado e invocado a crear condiciones favorables para la paz laboral y social entre quienes cuidan la salud y la vida de las personas, entendiendo que la principal reforma sanitaria de este siglo será el trabajo en equipo; no sin antes hacer notar que estos actos discriminatorios y de violencia deben ser rechazados, condenados, deplorados y sobre todo corregidos por todos los peruanos, puesto que según el artículo 323 del Código Penal, los actos discriminatorios son castigados con pena privativa de la libertad que puede ir de los dos hasta los cuatro años si se materializa mediante actos de violencia física y mental. 